\title{
ЭФФЕКТИВНОСТЬ СНА КАК ДЕТЕРМИНАНТА ЧУВСТВИТЕЛЬНОСТИ К ИНСУЛИНУ
}

\author{
Смирнова О.М.
}

\author{
ФГБУ «НИМЦ эндокринологии» Минздрава России, Москва
}

Ни один человек не может обойтись без сна. Во сне мозг работает в 10 раз активнее, чем днем. Венский невролог Константин фон Экономо (1876-1931) обнаружил, что у пациентов, умерших от летаргического энцефалита, в гипоталамусе промежуточного мозга присутствовали участки отмерших нервных клеток. Причем у пациентов, страдавших бессонницей, такие поврежденные участки находились в передней части гипоталамуса, тогда как у пациентов с гиперсомнией - в задней части. Предположение Экономо подтвердилось только в 1996 г. группой исследователей из Гарвардского университета, которая показала, что клетки передней части гипоталамуса составляют центр сна: они проявляют активность в период сна и молчат в период бодрствования. Опыты швейцарского физиолога Уолтера Рудольфа Гесса (1881-1973), показали, что электрическое раздражение определенных участков мозга кошек при помощи электродов приводит к изменению поведения животного от агрессии до защитных реакций. Раздражение некоторых участков гипоталамуса приводило к немедленному засыпанию животных. За проведенные исследования Уолтер Гесс и нейрохирург Эгаш Мониш, получили в 1949 г Нобелевскую премию.Высший центр регуляции эндокринных функций расположен в ядрах гипоталамуса, которые вырабатывают рилизинг-факторы - либерины и статины, которые регулируют работу аденогипофиза. Аденогипофиз, в свою очередь, вырабатывает ряд гормонов (СТГ, ТТГ, АКТГ, ФСГ, ЛГ), контролирующих работу желез внутренней секреции. Супраоптические и паравентрикулярные ядра продуцируют вазопрессин (АДГ) и окситоцин, которые по аксонам попадают в нейрогипофиз. Первым исследованием, где сообщалось о связи между недостаточным сном и смертностью было исследование 1,064,004 взрослых в возрасте от 30 до 80 лет было опубликовано в 1964 году, когда было обнаружено, что у тех, кто имел продолжительность сна более 7 часов_был самый низкий коэффициент смертности. Новые данные подтвердили важную роль сна в качестве модулятора метаболического гомеостаза. Влияние изменений в продолжительности сна, расстройство дыхания во время сна, и хронотип кардио-метаболической функции включает в себя широкий спектр факторов, охватывающих ожирение, резистентность к инсулину, СД2, метаболический синдром, риск сердечно-сосудистых заболеваний и смертности как у взрослых, так и у детей. Хронический недостаток сна является эндемическим и был объявлен в качестве проблемы общественного здравоохранения Центрами по контролю заболеваний. Последние данные опроса 2014 г. показали, что из 44306 опрошенных взрослых сообщили: 11,8\% - о 6 часах сна, 29,5\% - о 7 часах, 27,7\% - о 8 часах, 4,4\% - о 9 часах, 3,6\% - о 10 часах; с учетом продолжительности сна 7-9 часов, рекомендованных для возраста, только $65,2 \%$ сообщили о соблюдении рекомендуемой продолжительности здорового сна. Недостаточный сон широко распространен. Опрос 2014 г. "Sleep in America” показал, что 30\% детей школьного возраста в возрасте 6-11 лет (по сообщениям их родителей) спят меньше рекомендованных 9 часов. Хотя не каждое исследование обнаружило связь между продолжительностью сна и ожирением, большинство из них показали, что недостаточная продолжительность сна у детей ассоциируется с одновременным или долгосрочным риском ожирения - в младенчестве, раннем детстве, годах школьного образования и подростковом периоде. Имеется риск того, что транзиторная ИР, которая в норме возникает во время полового созревания, перейдет в постоянную ИР, особенно у подростков с ожирением и неблагоприятным перераспределением жира, и с наличием СД в семейном анамнезе, имеющиеся данные позволяют предполагать, что детерминантами возникновения ИР у подростков и ряда взрослых пациентов являются продолжительность сна, уровень физической активности и пищевое поведение. 